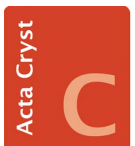

STRUCTURAL CHEMISTRY

ISSN 2053-2296

Keywords: rare earth-transition metal intermetallics; high $T_{\mathrm{C}}$ materials; quantum chemical calculations; structure-property relations

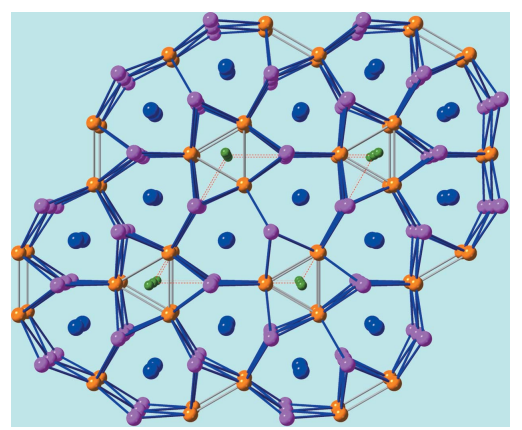

(C) 2019 International Union of Crystallography

\section{Understanding of magnetic ordering in Gd-rich compounds}

\author{
Tom Nilges*
}

Technical University Munich, Synthesis and Characterization of Innovative Materials, Department of Chemistry, Lichtenbergstrasse 4, 85748 Garching b. München, Germany. *Correspondence e-mail: tom.nilges@tum.de

Rare-earth transition-metal pnictides (RE-T-Pn) and related compounds are intriguing materials with a wide range of possible applications. Some randomly selected examples are Skutterudites (Evers et al., 1995) or the rare-earth iron arsenide 1111 superconductors (Kamihara et al., 2008). Another important class of materials with numerous reported candidates are $\mathrm{RE}_{6} \mathrm{~T} X_{2}$ representatives. In a combined crystal structure/electronic structure study on $\mathrm{Gd}_{6} \mathrm{FeBi}_{2}$, reported in Acta Crystallographica Section C (Zhang et al., 2019), a magnetic material with a high $T_{\mathrm{C}}$ well above room temperature was reported. Based on the selected elemental composition and its $\mathrm{Zr}_{6} \mathrm{CoAl}_{2}$-type structure (Kripyakevich et al., 1970) (prototype structure $\mathrm{K}_{2} \mathrm{UF}_{6}$; Zachariasen, 1948), a $T_{\mathrm{C}}$ of $350 \mathrm{~K}$ was observed. In a clear and precise way, the authors show that structure parameters like the Gd-Gd distance scales linearly with the $T_{\mathrm{C}}$ value for many structurally-related Gd compounds. In contrast, the title compound strongly deviates from this trend. After an excellent structure evaluation and the accurate determination of the gadolinium bond lengths, the authors substantiated and interpreted this finding with the aid of quantum chemical calculations (Fig. 1). They identified strong attractive $\mathrm{Gd}-\mathrm{Fe}$ interactions rather than weak $\mathrm{Gd}-\mathrm{Bi}$ ones as being responsible for the strong magnetic coupling. The present study clearly illustrates how important a precise structure determination is to interpret and understand physical properties. The exceptional high $T_{\mathrm{C}}$ in this case is fully understood after combining experimental diffraction and magnetic data with theory. Metallic $\mathrm{Gd}_{6} \mathrm{FeBi}_{2}$ has a very small and almost negligible homogeneity range and it can be regarded more as a line compound rather than an alloy. $\mathrm{Gd}_{6} \mathrm{FeBi}_{2}$ might be useful for a plethora of applications and the article of Zhang et al. (2019) may help to initiate the first efforts in that direction.

\section{References}

Evers, C. B. H., Jeitschko, W., Boonk, L., Braun, D. J., Ebel, T. \& Scholz, U. D. (1995). J. Alloys Compd. 224, 184-189.

Kamihara, Y., Watanabe, T., Hirano, M. \& Hosono, H. (2008). J. Am. Chem. Soc. 130, 3296-3297. Kripyakevich, P. I., Burnashova, V. V. \& Markiv, V. Ya. (1970). Dopov. Akad. Nauk Ukr. RSR Ser. $A$, 32, 828-831.

Zachariasen, W. H. (1948). J. Am. Chem. Soc. 70, 2147-2151.

Zhang, J., Kang, Y.-M., Shan, G. \& Bobev, S. (2019). Acta Cryst. C75, 562-567.

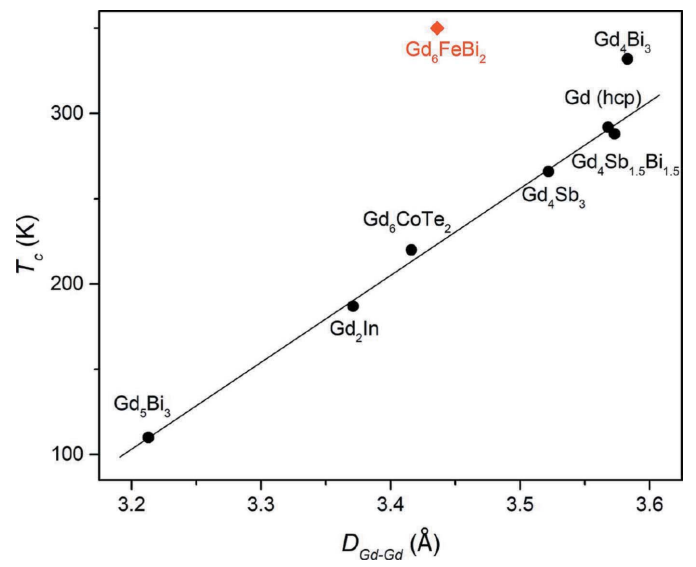

Figure 1

Magnetic ordering temperatures versus shortest gadolinium bond lengths of selected Gd-rich compounds according to and adapted from Evers et al. (1995). 